\title{
Pulse Plating of Copper from Deep Eutectic Solvents
}

\author{
T.A. Green, X. Su and S. Roy \\ Department of Chemical and Process Engineering, University of Strathclyde, Glasgow, \\ G1 1XJ, United Kingdom
}

The effect of pulse parameters on the deposition of copper from a chloride-based deep eutectic solvent (DES) was investigated. While satisfactory deposits could be obtained for some pulse conditions, at small duty cycles or long off-times the current efficiencies obtained were very low. These findings were consistent with a corrosion process occurring during the off-time, most likely the comproportionation reaction: $\mathrm{Cu}+\mathrm{Cu}^{\mathrm{II}} \mathrm{Cl}_{4}{ }^{2-} \rightarrow 2 \mathrm{Cu}^{\mathrm{I}} \mathrm{Cl}_{2}^{-}$. Initial experimental results were consistent with the corrosion rate being controlled by the transport of the $\mathrm{Cu}^{\mathrm{II}} \mathrm{Cl}_{4}{ }^{2-}$ species to the electrode surface. With this assumption, a simple corrosion model was developed to account for the observed loss in current efficiency as a function of the pulse conditions. While this model broadly predicts the observed results some discrepancy between the observed and measured were noted.

\section{Introduction}

In recent years there has been considerable interest in the deposition of metals, alloys and semiconductors from ionic liquids $(1,2)$. These melts possess a number of advantages over traditional aqueous solutions, especially for the deposition of reactive metals and where the current efficiency of the process is inherently low. Deep eutectic solvents (DES) are a new class of ionic liquids which possess low toxicity, low cost, and relatively good electrochemical characteristics (3). They have been used to deposit a wide range of materials and, unlike traditional ionic liquids, it is often possible to obtain acceptable deposit characteristics in the presence of significant amounts of water contamination. This makes them particularly suitable for industrial-scale plating.

Until now, most studies employing ionic liquids or DES have concentrated on DC plating and there have been relatively few reports of electrodeposition under pulse conditions (4,5). Significantly, ionic liquids have differing characteristics to aqueous solutions, particularly in terms of their double layer structure, mass transport properties, kinetics and conductivity. This suggests that pulse parameters developed for aqueous systems are unlikely to be optimal for electrodeposition from ionic liquids.

In this study the pulse plating of copper from a type-III deep eutectic solvent comprising choline chloride and ethylene glycol ('ethaline') is investigated. This is a useful 'model' system as there are numerous studies (6-9) of copper deposition under DC conditions. Additionally, the results can be conveniently compared to the existing literature on DC and pulse plating of copper from aqueous systems.

\section{Experimental}

This is a peer-reviewed, accepted author manuscript of the following research output: Green, T. A., Su, X., \& Roy, S. (2017). Pulse plating of copper from deep eutectic solvents. ECS Transactions. (in press) 
The DES electrolyte comprised $0.20 \mathrm{M} \mathrm{CuCl}_{2} .2 \mathrm{H}_{2} \mathrm{O}$ dissolved in a 1:2 molar ratio of choline chloride to ethylene glycol (6). All electrochemical experiments were performed in a single-compartment, jacketed glass cell maintained at a temperature of $25{ }^{\circ} \mathrm{C}$ with a thermostat bath. The working electrode (WE) was a steel or platinum rotating disk and experiments were typically performed at a rotation speeds of $\omega=300-1200 \mathrm{rpm}$. The counter electrode (CE) was a high purity copper rod, while a silver wire was used as a quasi-reference electrode (RE). The RE was mounted in a fritted glass tube containing pure ethaline, to prevent it from being etched by the $\mathrm{CuCl}_{2}$.

Pulse plating experiments were performed using a computer-controlled galvanostat and both the applied current and potential (vs. Ag wire RE) were measured. These experiments were performed at a rotation rate of $700 \mathrm{rpm}$, and the electrodes were weighed before and after deposition to assess the current efficiency. Pulse parameters were selected based on consideration of double layer charging effects and mass transport constraints (10-13). For initial experiments, on-times of $t_{\text {on }}=10,50,100$ and $200 \mathrm{~ms}$ and duty cycles of $\theta=0.10$, $0.20,0.30,0.50$ and 0.67 were used. Typically the peak current, $i_{\mathrm{p}}$, was set at $80 \%$ of the peak limiting current, $i_{\mathrm{pLIM}}$, and this also ensured that the average plating rate $\left(i_{\mathrm{av}}=i_{\mathrm{p}} \theta\right)$ did not exceed the steady-state limiting current, $i_{\text {LIM }}$.

\section{Results and Discussion}

The results of the initial pulse plating experiments are summarised in Figure 1. These show the appearance of the copper deposits and the measured current efficiency, $\varepsilon$, as a function of the pulse parameters. Figure 1 indicates that, in many cases, only partial plating was observed and often a copper annulus was visible at the edges of the disc with the steel substrate exposed at the centre. For duty cycles of $\theta=0.10$ (data not shown) it proved difficult to deposit any copper under any conditions, and only at relatively high duty cycles (i.e. $\theta>0.50$ ) was it possible to obtain a copper film over the entire disc surface. The current efficiency data also reflected the same trend. In many cases very low (or even 'negative') current efficiencies were observed at small duty cycles. In contrast, the highest current efficiencies were obtained at long duty cycles and short on-times and were comparable to those obtained under DC conditions (i.e. $\varepsilon=60 \%$ ).

The most plausible explanation for the results shown in Figure 1 is that a corrosion reaction is dissolving copper during the off-time. This explains why partial plating and low $\varepsilon$ values are observed under conditions where the duty cycle is low and/or the off-time is long. The 'annulus' effect arises because the material distribution at the RDE is inherently not uniform. Even if copper corrodes uniformly in the off-time, the thinner deposit at the disc center will be removed first. Similarly, negative current efficiency values result from etching of the underlying steel substrate.

The occurrence of a corrosion reaction was verified by measuring the weight loss of both the copper plated and un-plated steel substrates in the electrolyte solution at a rotation speed of $700 \mathrm{rpm}$. These results indicated that the electrolyte corroded the steel substrate and copper at an appreciable rate, but in pure ethaline that rate of corrosion was negligible. This is in agreement with a previous study (14) which showed that the corrosion rate of

[Type here] 
steel in pure ethaline (containing dissolved $\mathrm{O}_{2}$ but not $\mathrm{CuCl}_{2}$ ) was extremely low. The necessity of $\mathrm{CuCl}_{2}$ to the corrosion processes suggests a comproportionation reaction of the following type is occurring in the off-time:

$$
\mathrm{Cu}+\mathrm{Cu}^{\mathrm{II}} \mathrm{Cl}_{4}{ }^{2-} \rightarrow 2 \mathrm{Cu}^{\mathrm{I}} \mathrm{Cl}_{2}^{-}
$$

This reaction is thermodynamically favourable in chloride-containing DES and similar reactions have also been observed in other ionic liquids $(15,16)$. It is also likely to occur for other chloride-containing ionic liquids containing metals salts (e.g. $\mathrm{AuCl}_{3}$ and $\mathrm{FeCl}_{3}$ ) which are susceptible to comproportionation. Comparable corrosion processes are also observed in aqueous systems. For example, the etching of copper in $\mathrm{CuCl}_{2}$ solutions is routinely used to manufacture PCBs (17). Similarly, during the pulse plating of copper from concentrated $\mathrm{HCl}$ solutions, corrosion of the deposit in the off-time was reported (18). This initially led to the formation of an insoluble salt film of $\mathrm{CuCl}$, but at long off-times the film dissolved to form soluble chloro-complexes. Finally, during the pulse plating of binary alloys, corrosion in the off-time by a displacement reaction has also been observed $(19,20)$.

\begin{tabular}{|c|c|c|c|c|}
\hline & $t_{o n}=10 \mathrm{~ms}$ & $t_{o n}=50 \mathrm{~ms}$ & $t_{o n}=100 \mathrm{~ms}$ & $t_{o n}=200 \mathrm{~ms}$ \\
\hline \multicolumn{5}{|l|}{$\theta=0.2$} \\
\hline & $\varepsilon=40.7 \%$ & $\varepsilon=26.5 \%$ & $\varepsilon=9.2 \%$ & $\varepsilon=-23.3 \%$ \\
\hline \multicolumn{5}{|l|}{$\theta=0.3$} \\
\hline & $\varepsilon=44.4 \%$ & $\varepsilon=21.7 \%$ & $\varepsilon=13.7 \%$ & $\varepsilon=-1.7 \%$ \\
\hline \multicolumn{5}{|l|}{$\theta=0.5$} \\
\hline & $\varepsilon=57.5 \%$ & $\varepsilon=53.2 \%$ & $\varepsilon=45.6 \%$ & $\varepsilon=30.4 \%$ \\
\hline \multicolumn{5}{|l|}{$\theta=0.67$} \\
\hline & $\varepsilon=61.1 \%$ & $\varepsilon=57.4 \%$ & $\varepsilon=56.2 \%$ & $\varepsilon=45.9 \%$ \\
\hline
\end{tabular}

Figure 1. The appearance of the electrodeposited copper and the apparent current efficiency, $\% \varepsilon$, as a function of pulse parameters.

Further evidence for the corrosion process is evident from the time dependence of the electrode potential, E, during the pulse cycle (Figure 2). In the off-time, the electrode [Type here] 
potential initially adopts a value of $E=-0.20 \mathrm{~V}$. However, at longer off-times the potential slowly transitions to a value of $E=-0.10 \mathrm{~V}$. These two values correspond closely to the measured corrosion potential, $E_{\text {corr, }}$ of the copper and steel substrate, and indicate that at long off-times the $\mathrm{Cu}$ deposit can be completely removed.

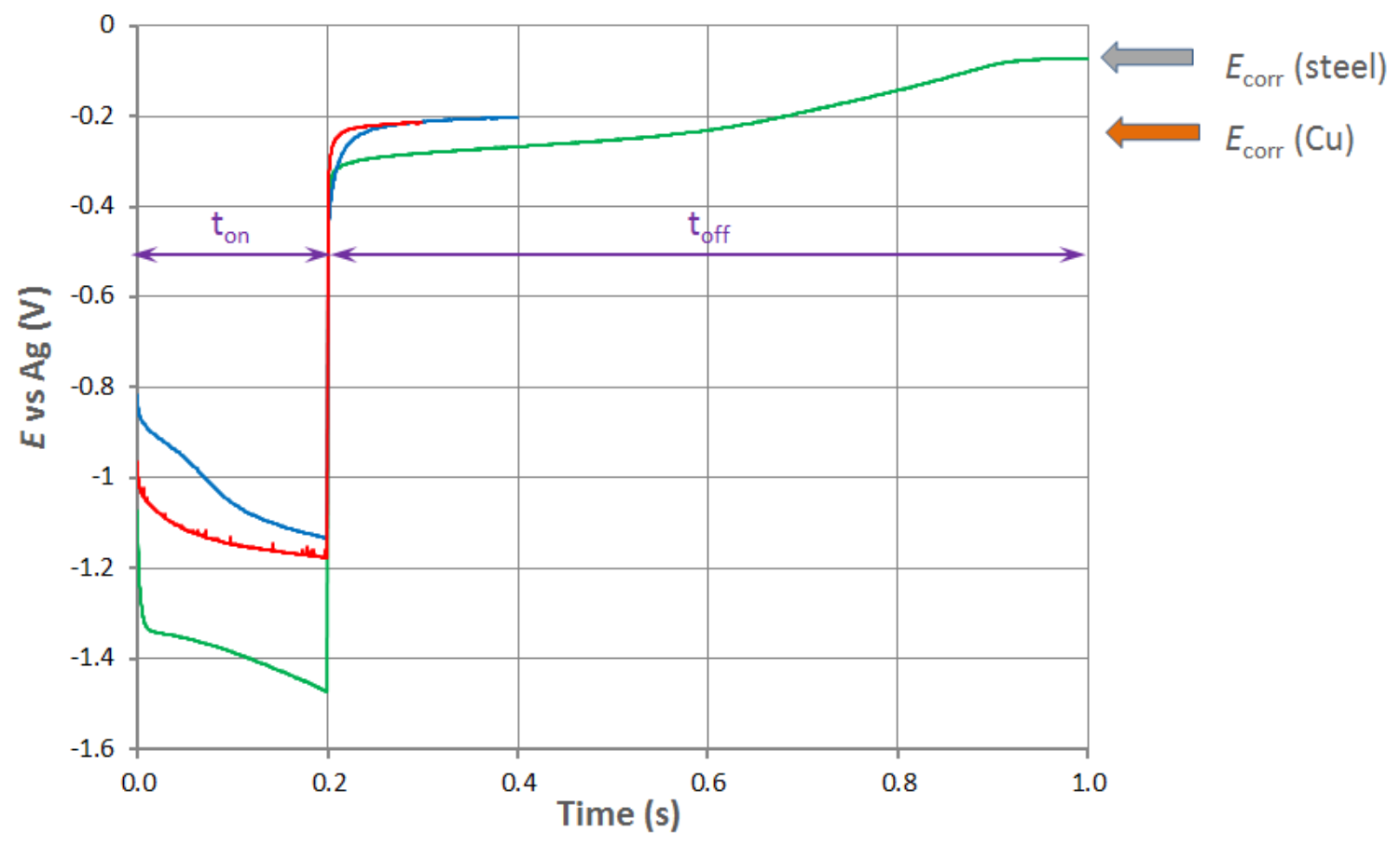

Figure 2. Time dependence of the electrode potential, $E$, during the pulse cycle for $t_{\text {on }}=$ $200 \mathrm{~ms}$ and at various duty cycles: $\theta=0.67$ (solid line); $\theta=0.50$ (long dashed line) and $\theta$ $=0.20$ (short dashed line).

The characteristics of the corrosion reaction are best examined by referring to the polarisation plot for the electrolyte solution (Figure 3). Note that this data was recorded at a platinum electrode to enable the anodic processes to be clearly shown. The electrochemical reactions corresponding to each anodic and cathodic process are shown and the position of the arrows indicates the approximate current/potentials adopted during the on and off-times. In the off-time, the electrode can adopt a mixed potential ( $\left.E_{\text {corr }}\right)$ corresponding to the reactions:

$$
\begin{gathered}
\mathrm{Cu}+2 \mathrm{Cl}^{-} \rightarrow \mathrm{Cu}^{\mathrm{I}} \mathrm{Cl}_{2}^{-}+\mathrm{e}- \\
\mathrm{Cu}^{\mathrm{II}} \mathrm{Cl}_{4}{ }^{2-}+\mathrm{e}-\rightarrow \mathrm{Cu}^{\mathrm{I}} \mathrm{Cl}_{2}^{-}+2 \mathrm{Cl}^{-}
\end{gathered}
$$

The overall corrosion reaction corresponding to these half reactions is that shown in equation [1]. Figure 3 also indicates that the corrosion rate is controlled by the mass transport of the $\mathrm{Cu}(\mathrm{II})$ species to the electrode surface. Independent measurements (not

[Type here] 
shown here) indicate that $i_{\text {corr }}$ increases and $E_{\text {corr }}$ shifts to more positive values with increasing rotation rate which are consistent with this mechanism.

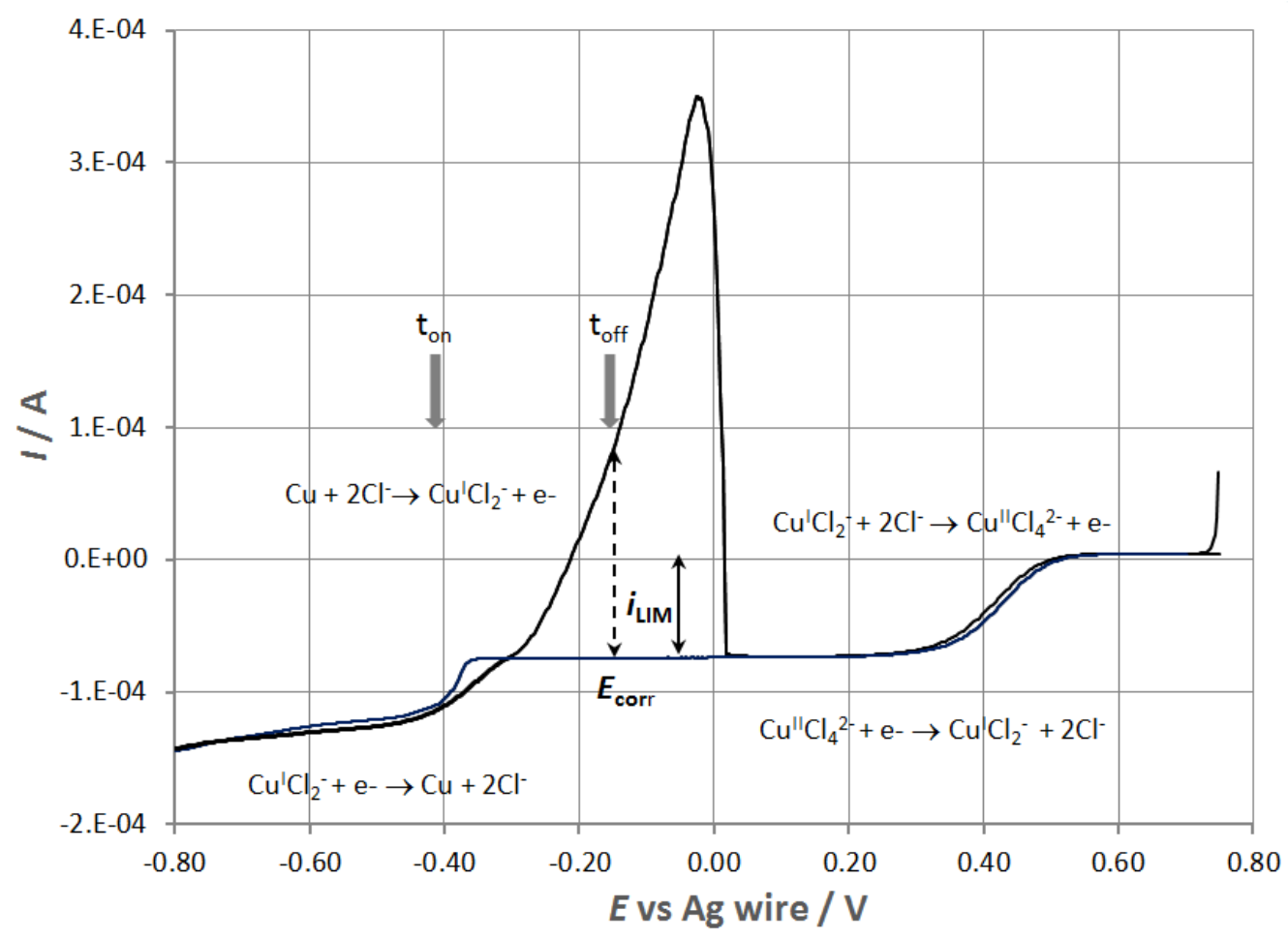

Figure 3. Steady-state polarisation curve for a platinum electrode in $0.20 \mathrm{M} \mathrm{CuCl}_{2}$ in ethaline $(\omega=700 \mathrm{rpm})$. The mixed potential developed in the off-time occurs at $E=E_{\text {corr. }}$.

Using this information we can develop a simple corrosion model which relates the apparent current efficiency, $\varepsilon$, with the pulse parameters. The major assumptions of the model are that the corrosion rate is constant in the off-time and that it has a rate governed by the limiting current for reaction [3]. This can be justified on the grounds that during the on-time the $\mathrm{Cu}^{\mathrm{II}} \mathrm{Cl}_{4}{ }^{2-}$ is always being reduced under limiting current conditions. In the offtime the reaction continues to occur at the same rate as it is now coupled to the anodic dissolution reaction [2]. The concentration profile for the $\mathrm{Cu}$ (II) species is therefore held close to the value it adopted in the on-time. Using these assumptions we can derive the simple expression:

$$
\varepsilon=\varepsilon^{\prime}-2 i_{\text {corr }}(1-\theta) / i_{\mathrm{p}} \theta
$$

where $\varepsilon$ ' is the current efficiency during the on-time. Therefore, a plot of $\varepsilon$ versus $(1-\theta) /$ $i_{\mathrm{p}} \theta$ should result in a straight line with a slope of $i_{\text {corr }}$ and an intercept corresponding to $\varepsilon$ '. The results of this analysis are shown in Figure 4 and Table I.

While these results qualitatively support the proposed model, there are two main issues. Firstly, $i_{\text {corr }}$ is lower than the experimentally determined value of $i_{\mathrm{LIM}}=3.2 \mathrm{~mA} \mathrm{~cm}{ }^{-2}$ for [Type here] 
reaction [3]. Secondly, there is an unexpected dependence of $i_{\text {corr }}$ on the pulse parameters. Interestingly, there is some evidence that for long pulse periods the value of $i_{\text {corr }}$ may approach $i_{\text {LIM }}$. However, the overall conclusion must be the proposed model does not quantitatively account for the observed results and further development is required.

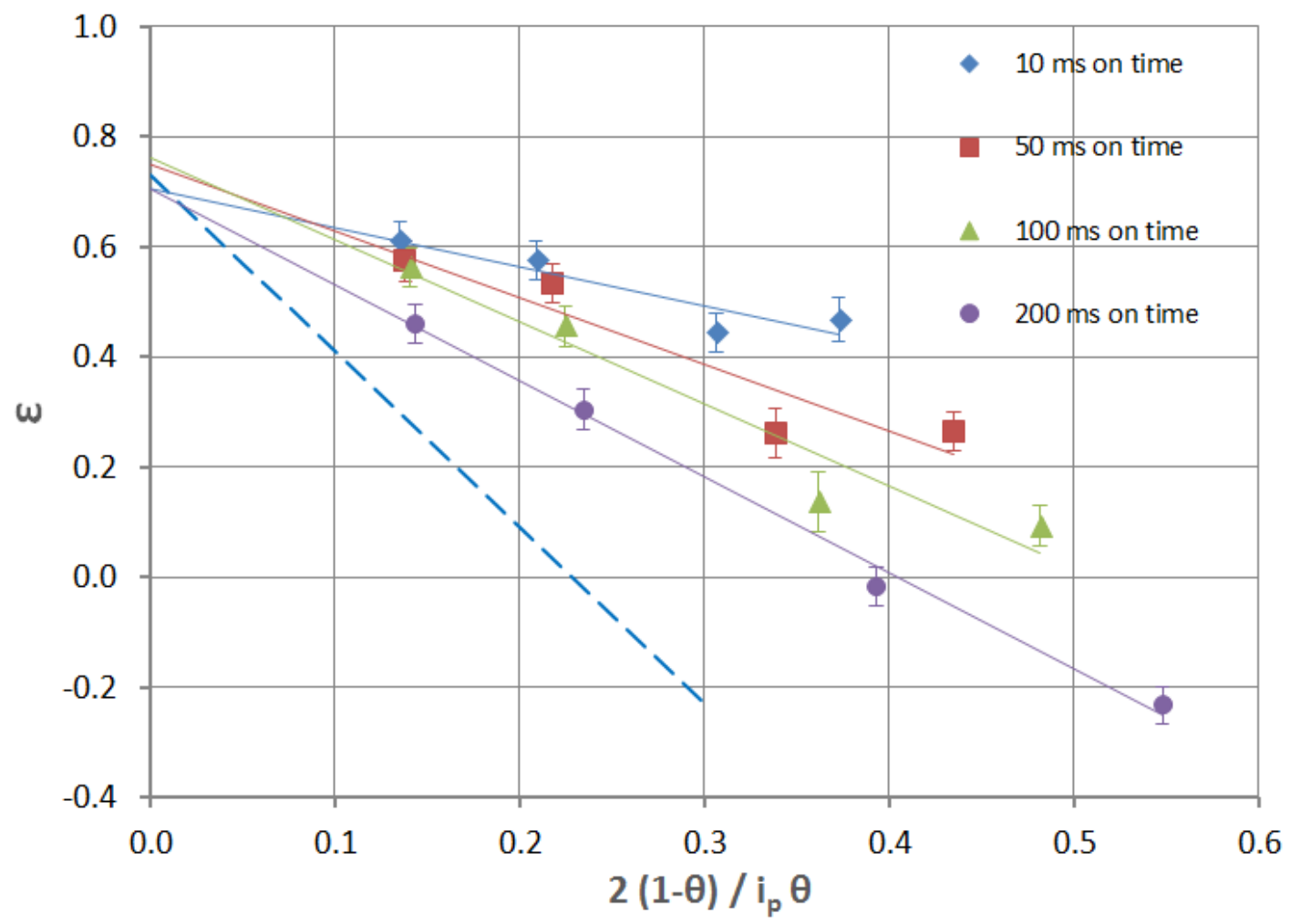

Figure 4. The variation in the apparent current efficiency, $\varepsilon$, as a function of pulse parameters (equation [4]). The dotted line corresponds to $i_{\text {corr }}=i_{\mathrm{LIM}}=3.2 \mathrm{~mA} \mathrm{~cm}^{-2}$.

The occurrence of corrosion reactions during pulse plating is generally not desirable, but a number of strategies are available to minimise the effect. Firstly, corrosion could be reduced by operating at fairly long duty cycles (i.e. $\theta>0.50$ ). However, this limits the parameter space were the process can be optimised, and effectively DC conditions are being approached. Another strategy is to use non-chloride deep eutectic solvents which would also prevent the comproportionation reaction from occurring. Unfortunately, many of these systems (e.g. citrate or acetate) have relatively poor conductivity and transport properties compared to chloride systems (21). Finally, it may be feasible to maintain the current (or potential) in the off-time to a value that prevents dissolution, but also allow for minimal deposition.

TABLE I. Values of $i_{\text {CORR }}$ and $\varepsilon$ ' extracted from the linear plots in Figure 4.

\begin{tabular}{ccc}
\hline $\mathbf{t}_{\text {on }} / \mathbf{m s}$ & $\boldsymbol{i}_{\text {corr }} / \mathbf{m A ~} \mathbf{~ c m}^{-2}$ & $\boldsymbol{\varepsilon}^{\prime}$ \\
\hline 10 & 0.71 & 0.70 \\
50 & 1.21 & 0.75 \\
100 & 1.49 & 0.76
\end{tabular}

[Type here] 


\section{Conclusions}

Pulse plating of copper from a chloride-containing deep eutectic solvent has been demonstrated. While acceptable deposits could be obtained for some pulse conditions, at small duty cycles low current efficiencies and partial plating was observed. This was attributed to the occurrence of a corrosion (comproportionation) reaction during the offtime. A simple corrosion model was proposed and, while this qualitatively explained the results, a number of discrepancies with the experimental data were noted, suggesting that

further refinements of the model are needed. Finally, a number of strategies for minimising corrosion effects during pulse plating have been proposed.

\section{References}

1. F. Endres, D. MacFarlane and A. Abbott, Electrodeposition from Ionic Liquids, Wiley-VCH, Weinheim (2008).

2. A.P. Abbott and K.J. McKenzie, Phys. Chem. Chem. Phys, 8, 4265 (2006).

3. E.L. Smith, A.P Abbott and K.S. Ryder, Chemical Reviews, 114, 11060 (2014).

4. A. Ispas and A. Bund, Trans IMF, 90, 298 (2012).

5. A. Ispas and A. Bund, Interface, Spring 2014.

6. S. Ghosh and S. Roy, Surface Coat. Technol., 238, 165 (2014).

7. A.P. Abbott, K.E. Ttaib, G. Frisch, K.J. McKenzie and K.S. Ryder, Phys. Chem. Chem. Phys., 11, 4269 (2009).

8. B.G. Pollet, J.Y. Hin, T.J. Mason, Electrochim. Acta., 53, 4828 (2008).

9. A-M. Popescu, V. Constantin, A. Cojocaru and M. Olteanu, Rev. Chim., 62, 206 (2011).

10. J. C Puippe and F. Leaman, Theory and Practice of Pulse Plating, AESF, Orlando, FL (1986).

11. W.E.G. Hansal and S. Roy, Pulse Plating, Eugen Leuze, Bad Saulgau (2012).

12. S. Roy and D. Landolt, J. Appl. Electrochem., 27, 299 (1997).

13. T.A. Green and S. Roy, Trans IMF, 95, 46 (2017).

14. A.P. Abbott, E.I. Ahmed, R.C. Harris and K.S. Ryder, Green Chem., 16, 4156 (2016).

15. K. Murase, K. Nitta, T. Hirato and Y. Awakura, J. Appl. Electrochem., 31, 1089 (2001).

16. D. Lloyd, T. Vainikka, L. Murtomaki, K. Kontturi and E. Ahlberg, Electrochim. Acta., 56, 4942 (2011).

17. M. Georgiadou and R. Alkire, J. Electrochem. Soc., 140, 1340 (1993).

18. C.W. Yeow and D.B. Hibbert, J. Electrochem. Soc., 130, 786 (1983).

19. S. Roy, D. Landolt and M. Matlosz, J. Electrochem. Soc., 141, 1509 (1994).

20. S. Roy, Surf. Coat. Technol., 105, 202 (1998).

21. R. Bernasconi, M. Zebarjadi and L. Magagnin, J. Electroanal. Chem, 758, 163 (2015).

[Type here] 